\title{
Adaptive management rules for Pinus nigra Arnold ssp. salzmannii stands under risk of fire
}

\author{
José Ramón González-Olabarria $^{1}$ • Jordi Garcia-Gonzalo ${ }^{1,2}$ • Blas Mola-Yudego ${ }^{3,4}$. \\ Timo Pukkala ${ }^{4}$
}

Received: 15 March 2016 / Accepted: 6 June 2017 / Published online: 3 July 2017

(C) INRA and Springer-Verlag France SAS 2017

\begin{abstract}
- Key message We generate flexible management rules for black pine stands, adaptable to alternative stand management situations and entailing thinnings, final-felling, and salvage cuts, based on the results on 270 stand level optimizations.

- Context Forest management instructions often rely on the anticipated prediction of the stand development, which poses a challenge on variable economic and environmental conditions. Instead, an alternative approach to better adapt forest management decisions to changing conditions is defining flexible rules based on thresholds that trigger management operations.

- Aims This article develops rules for the adaptive management of $P$. nigra stands in Catalonia (Spain) addressing the risk of fire and post-fire forest management.

- Methods The stochastic version of the simulationoptimization system RODAL was used to optimize the man-

\section{Handling Editor: Eric Rigolot}

Contribution of the co-authors Jordi Garcia-Gonzalo, Blas MolaYudego, and Timo Pukkala actively participated in the design of the study, discussion of the results, revision, and editing of the manuscript. In addition, Timo Pukkala modified the simulator-optimization system to include post-fire rules, and to generate the outputs that were later used for modeling purposes.
\end{abstract}

José Ramón González-Olabarria

jr.gonzalez@ctfc.es

Jordi Garcia-Gonzalo

j.garcia@ctfc.es

Blas Mola-Yudego

blas.mola@uef.fi

Timo Pukkala

timo.pukkala@uef.fi agement of forest stands in three sites under different fire probability levels. A total of 270 optimizations were done varying site fertility, fire probability, and economic factors. The results of the optimizations were used as the basis of flexible forest management rules for adaptive stand management.

- Results The developed management rules defined the basal area limit for thinning, the thinning intensity, the mean tree diameter at which regeneration cuttings should start, and the basal area below which a salvage cutting should be done. Fire risk was not a significant predictor of the models for thinning and final cutting rules.

- Conclusion The presented rules provide a flexible tool for forest management during the stand development and under changing conditions when the management objective is to maximize economic profitability of timber production.

Keywords Optimization · Stochastic simulation · Management rules $\cdot$ Wildfire risk
1 Forest Science Centre of Catalonia, Ctra St. Llorenç de Morunys, Km 2, ES-25280 Solsona, Spain

2 School of Agriculture, Forest Research Centre, University of Lisbon, Tapada da Ajuda, 1349-017 Lisbon, Portugal

3 Department of Forest and Climate, Norwegian Institute of Bioeconomy Research (NIBIO), PO Box 115, 1431 Ås, Norway

4 School of Forest Sciences, University of Eastern Finland, PO Box 111, FI 80101 Joensuu, Finland 


\section{Introduction}

Black pine (Pinus nigra Arnold ssp. salzmannii) forests cover about 134,000 ha in Catalonia (Spain), representing $12 \%$ of the forested area of this region (Palahí and Grau-Corbí 2003). During 1991-2002, close to one fourth of the black pine forests were affected by wildfires (Gonzalez et al. 2006), with $42 \%$ average tree mortality rate (González et al. 2007). This makes $P$. nigra one of the most affected tree species by wildfires. In addition, P. nigra, in contrast to, e.g., P. halepensis, is a non-fire-prone seeder, and therefore, large fires are an obstacle for achieving natural regeneration (Ordóñez et al. 2005, 2006), which may jeopardize the persistence of black pine forest in the region due to displacement by other tree species more adapted to fire (Puerta-Piñero et al. 2012).

Black pine has historically been subjected to selective cuttings, targeting the best trees for pole production. These practices generated multi-layered forest structures facilitating the occurrence of high-intensity crown fires (González-Olabarria et al. 2008). According to the Council Directive 92/43/EEC on the Conservation of natural habitats and of wild fauna and flora, this type of management, in addition to the increasing occurrence of large and destructive fires (González and Pukkala 2007), has already been recognized as the main threat for the persistence of autochthonous black pine forests. An effective way to mitigate the effects of fire are operational management rules addressing changes in factors that may affect the optimal management such as economic conditions and fire risk regime, while at the same time achieving the maximum revenue. This should result in a better basis for an adaptive and economically sustainable management of the $P$. nigra forests, contributing to the viability of these forests in Catalonia.

The development of management instructions for forest stands is often based on the assumption that the current economic and environmental conditions will remain constant or evolve overtime following a known trend. Under this assumption, the development of a forest stand, subject to a defined management schedule, can be predicted fairly well and its management schedule can be optimized. Early studies dealing with the inclusion of fire risk into stand level optimization problems often relied on this deterministic approach where the risk of fire is assumed to be known, and constant over time, its impact being a reduction in the expected income by the pre-defined probability of fire occurrence (e.g., Routledge 1980; Martell 1980; Reed 1984; Reed and Errico 1985; Caulfield 1988; Englin et al. 2000; Kuboyama and Oka 2000). More recently, however, stochastic simulation has been applied aiming at reflecting the variability in the occurrence and impact of fires, generating multiple scenarios and using the expected income as the objective function (González et al. 2005, González-Olabarria et al. 2008; Hyytiäinen and Haight 2010; Garcia-Gonzalo et al. 2014).
In both cases, the resulting optimal stand management often translates into defined cutting years and cutting intensities (Pukkala et al. 1998), even when the development of the stand is subject to the risk of sudden destruction due to wildfires (González et al. 2005; Pasalodos-Tato et al. 2009; GarciaGonzalo et al. 2014). However, surrounding factors may change drastically, and those fixed management rules considered as optimal under certain conditions would require a revision. In these cases, the results from anticipatory optimizations lack the flexibility to adapt management to new realities. Anticipatory optimization, even when it is stochastic, does not produce rules that would help the manager to react to changing economic and environmental situations (Lohmander 2007; Ferreira et al. 2014).

When economic profitability is maximized, shortening the rotation length is often considered the best option when the discount rate or the risk of disturbances increases (Martell 1980; Routledge 1980; Reed 1984; Reed and Errico 1985; González et al. 2005), or the quality of the site, in terms of growth, increases (Palahi and Pukkala 2003). However, if the degree of damage caused by fire depends on tree size and stand structure, increasing fire occurrence does not necessarily lead to shortening optimal rotations (Pasalodos-Tato et al. 2010), and a partial fire damage may modify the optimal management (Ferreira et al. 2014). If the optimized variables are properly set, stochastic optimization may show the influence of external conditions and help adapt forest management to changes in uncertain uncontrollable factors (ZubizarretaGerendiain et al. 2015; Pukkala 2015). Adaptive management rules based on stochastic stand level optimization techniques will improve decision making in risky environments (Pukkala and Kellomäki 2012), especially when the management rules are based on easily measured variables that describe the real development of the forest.

The present paper aims at the establishment of management rules for P. nigra stands in Catalonia addressing the risk of fire, helping foresters to adapt the management of forest stands to specific conditions, depending on changes in economic and fire-related factors. The analysis is based on a stochastic version of the simulation-optimization system RODAL (Palahi and Pukkala 2003). Data sets consisting of a high number of optimal management schedules were used as the basis for formulating flexible forest management rules, fitted as regression models, and adapted to multiple planning problems.

\section{Material and methods}

\subsection{The simulation-optimization system}

A modified version of the simulation-optimization system RODAL was used to obtain optimal management 
schedules for even-aged P. nigra stands under the risk of fire, when the objective was to maximize of the soil expectation value (Faustmann 1849). The RODAL system consists of a stand growth and yield simulator that predicts the evolution of a stand under a management regime
(Fig. 1), using the models of Palahí and Grau-Corbí (2003) and estimates revenues associated with the selected management, based on roadside timber prices minus logging and transportation costs according to Solano et al. (2007).

Roadside timber price $\left(€ / \mathrm{m}^{3}\right)=d^{2} /\left(0.15 d+0.025 d^{2}\right)$

Felling cost $\left(€ / \mathrm{m}^{3}\right)=\exp (3.406-0.568 \ln (d)+0.01$ slope $)$

Transportation cost $\left(€ / \mathrm{m}^{3}\right)=\exp \left(4.396-0.11 d^{0.5}+0.012\right.$ slope +0.001 dist $)$

where $d$ is the diameter of the tree (cm), slope is the percentage altitude change per unit distance (\%), and dist is the distance to the nearest road $(\mathrm{m})$.

In order to incorporate the risk of fire, it includes the possibility of simulating stochastic fires with a given fire occurrence probability. When a fire event is simulated, the system predicts the tree mortality by using the management-dependent mortality model of González et al. (2007). The system allows several post-fire options such as keeping on growing the stand, implementing a complete salvage cutting and a posterior planting, or starting the regeneration cuttings if the post-fire stand has at least 200 surviving trees $\mathrm{ha}^{-1}$ with a diameter at breast height over $17 \mathrm{~cm}$ (Ordoñez et al. 2006). Each simulation continues until one full rotation is accomplished (Fig. 1) or until the number of fire occurrences is 10 . In all cases, the soil expectation value $(S E V)$ is calculated assuming that the simulated schedule is repeated to infinity.

In addition, the RODAL system includes a non-linear optimization algorithm ' that finds the optimal combination of the decision variables. In this study, the decision variables were as follows:
For thinnings

- Basal area at which thinning is conducted, as a function of mean tree diameter $(D m): B A_{\text {thin }}=\mathrm{a}_{1}+\mathrm{b}_{1} D m$, where $\mathrm{a}_{1}$ and $b_{1}$ are the optimized decision variables

- Percentage of the basal area to be cut as a function of mean tree diameter: Thin $\%=\mathrm{a}_{2}+\mathrm{b}_{2} \mathrm{Dm}$, where $\mathrm{a}_{2}$ and $\mathrm{b}_{2}$ are the optimized decision variables

For final cut

- Mean diameter of the stand at which the first regenerative cut is conducted

For salvage

- Stand basal area below which a salvage cutting is conducted, as a function of mean tree diameter: $B A_{\text {salvage }}=\mathrm{a}_{3}+$ $\mathrm{b}_{3} D m$, where $\mathrm{a}_{3}$ and $\mathrm{b}_{3}$ are the optimized decision variables.

The optimization algorithm used to find the optimal combination of these variables was the direct search method of
Fig. 1 Choices for simulating stand development: without fires (a), with a fire but no salvage cutting $(b)$, and with a fire followed by salvage cuttings $(c)$

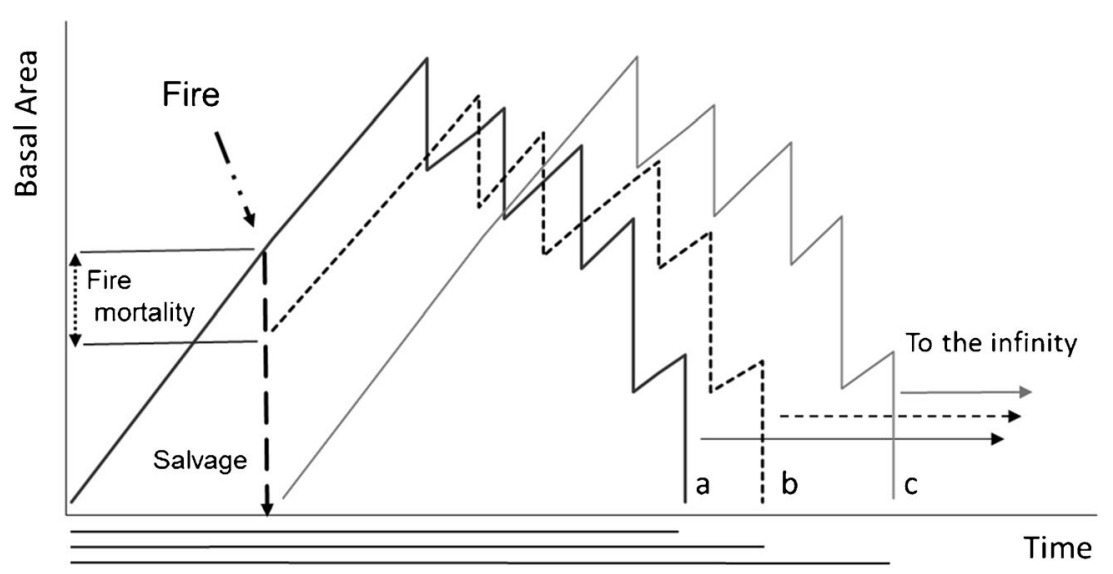

Lenght of complete simulation 
Hooke and Jeeves (1961). This method starts from a base point, which is the best solution of a number of random searches. It combines an exploratory search that alters one decision variable per move in the direction of the coordinate axes and a pattern search that alters the decision variables in the direction defined by the previous base point and the best point found during the exploratory search (see, e.g., Bazaraa and Shetty 1979). The parameters of the search used in the study were the same as in González et al. (2005) and González-Olabarria et al. (2008). The objective function was the mean soil expectation value of 500 stochastic simulations, when fire risk was considered, and from a single deterministic simulation if no risk of fire was considered. In the case of salvage cutting, the simulator used a $25 \%$ depreciation for all timber assortments (Arenas-Ruiz and Izquierdo-Osorio 2007). After salvage cutting, regeneration was assumed to be done by planting (with a cost of $1500 \mathrm{EUR} \mathrm{ha}^{-1}$ ) or naturally from the seed dispersed by adjacent stand. In the latter case, there was no regeneration cost after salvage cutting.

In the system (Fig. 2), the optimal management was defined by the thinning schedule and the moment when regeneration cuttings are started, following a shelter wood cutting method. The moment when a thinning was implemented was defined by the basal area at which thinning is conducted, implying that the number of thinnings was neither pre-defined or optimized, but depended on how many times the stand reached an optimized thinning limit. Regarding the parameters defining the shelterwood method (i.e., timing and intensity of the regeneration cuts), only the timing of the first regenerative cut was optimized. The other parameters followed commonly used recommendations, according to which the remaining trees should be removed in two cuttings during a 20 -year period (see Palahi and Pukkala 2003).

\subsection{Generating rules for adaptive forest management}

In order to assess the impact of varying conditions on the optimal management of P. nigra stands, optimizations were done for a wide range of scenarios considering factors that may affect the optimal management. These scenarios are the result of combining three different initial stands with similar structure in terms of diameter distribution (1050 trees ha ${ }^{-1}$ and 12.3-cm mean diameter) but varying in site fertility (poor, medium, or good), nine different discount rates (ranging from 0.1 to $4.1 \%$ with $0.5 \%$ interval), two different thinning techniques (high thinning or low thinning), and two different planting costs (no cost and 1500 EUR ha ${ }^{-1}$ ). Three different fire scenarios were assumed, expressed as variations in the 5-year probability of fire occurrence (no fire, 0.02, and 0.05), their selection being based on the estimated mean fire occurrence for P. nigra stands in Catalonia $(0.038$ according to Gonzalez et al. 2006). The permutations of these factors resulted in 270 scenarios. An optimization was carried out for each scenario, which resulted in the optimal management under the specific conditions. Natural regeneration was used always in the no fire scenarios, and therefore, no optimizations were done with the planting option.

Based on the results of the 270 optimizations, a database was generated for modeling the optimal management and expected SEV. From the 270 optimizations, 54 optimizations were done assuming a fire risk-free environment (i.e., deterministic), while 216 optimizations used a fire occurrence probability of 0.02 or 0.05 , requiring stochastic simulations. The database was used to develop
Fig. 2 Structure of the fireadjusted RODAL simulationoptimization system

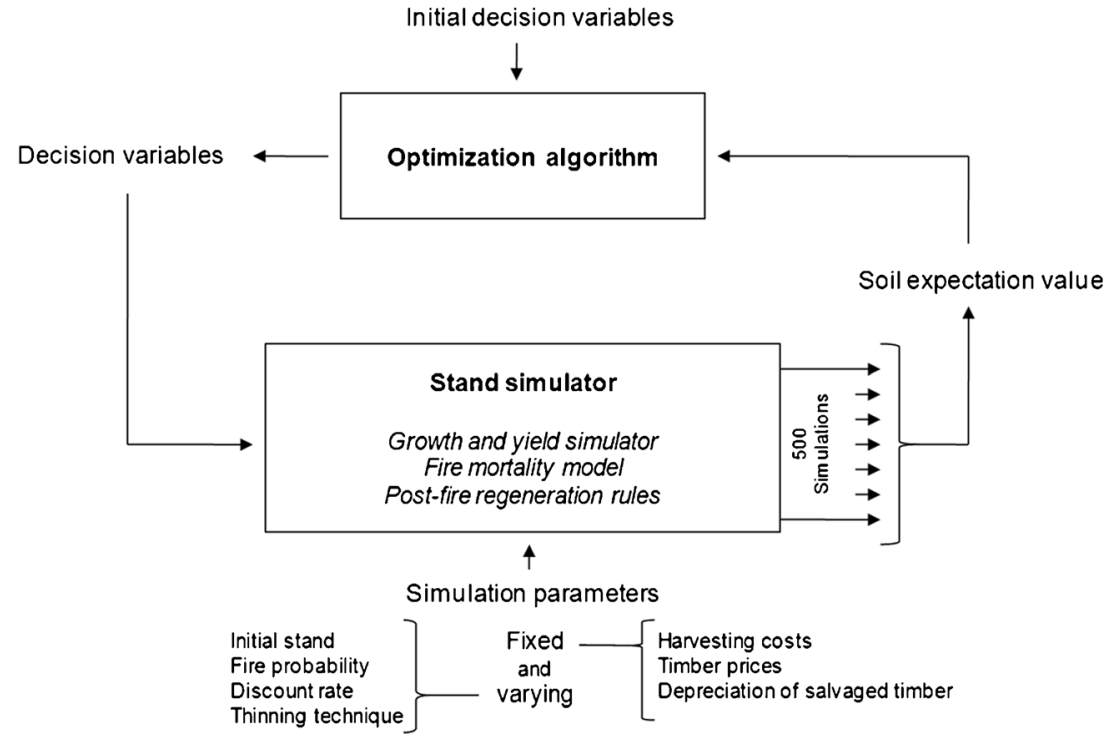


models for thinning basal area, thinning intensity, diameter of the stand at the first regenerative cut, and expected SEV (example in Table 3).

Another data set was generated from the stochastic simulations for each optimal combination of the decision variables in those problems where fire risk was considered (216 optimizations $\times 500$ stochastic simulations). This database was used to model the basal area below which salvage cutting is optimal decision. The $216 \times 500$ stochastic simulations included 22,108 fire events.

Easily retrieved stand variables were used as predictors. The combination of predictors for each model was systematically assessed through stepwise regression. The selection of the candidate predictors was based on their statistical significance (at the 0.05 level) and predictive power, and the final models had to be parsimonious. The models defined the basal area limit that activates a thinning treatment, the intensity of the thinning, the stand mean diameter at which regeneration cuttings should start, and a basal area limit for salvage cutting. Finally, a model was developed to approximate the expected soil expectation value of the management schedule.

\section{Results}

\subsection{Optimal stand management}

As expected, the mean annual increment under economically optimal management depended on site quality with an average increment of $2.3 \mathrm{~m}^{3} \mathrm{ha}^{-1}$ per year on poor sites, $3.5 \mathrm{~m}^{3} \mathrm{ha}^{-1}$ per year on medium sites, and $5.1 \mathrm{~m}^{3} \mathrm{ha}^{-1}$ per year on good sites. The average number of fires varied depending on the 5-year fire probably set as simulation parameter. For example, when the 5 -year fire probability was 0.02 , the average number of fires per simulation was 0.38 of which 0.04 were recurrent fires, which occurred once the stand had suffered from previous fire episodes. When the 5year fire probability was 0.05 , the number of fires per simulation increased to 1.05 , with 0.06 corresponding to recurrent fires. The average rotation length was 92.4 years, varying from a minimum of 60 years to a maximum of 175 years. The optimizations showed that thinning was not always included in the optimal management schedule; of the 270 management regimes optimized, 125 included thinning treatments, of which 67 included two or more thinnings.

\subsection{Management rules}

Two models were developed for defining the thinning regime, the first model for the basal area limit that activates the thinning treatment (Eq. 1) and the second model for the percentage of removed basal area (Eq. 2). A third model was developed for the mean diameter at which regeneration cuts should start (Eq. 3). Finally, a post-fire management model was developed for the basal area of surviving trees below which, in case of fire, a salvage cutting should be conducted (Eq. 4):

$$
\begin{aligned}
& B A_{\text {th }}=\exp \left(\begin{array}{r}
b_{0}+b_{1} \sqrt{D m}+b_{2} \text { Good }+b_{3} \text { Poor } \\
+b_{4} \text { DR }+b_{5} \text { High }
\end{array}\right) \\
& C U T_{\%}=b_{0}+b_{1} \text { BA }+b_{2} \text { Good }+b_{3} \text { Poor }+b_{4} \text { DR } \\
&+b_{5} \text { High } \\
& D m_{\text {reg }}= b_{0}+b_{1} \text { BA }+b_{2} \text { Good }+b_{3} \text { Poor }+b_{4} \text { DR } \\
&+b_{5} \text { High }
\end{aligned}
$$

$$
\begin{aligned}
B A_{s v}= & b_{0}+b_{1} D m+b_{2} \text { Poor }+b_{3} D R+b_{4} \text { High } \\
& +b_{5} \text { Damage }
\end{aligned}
$$

where $B A_{t h}$ is the basal area at which thinning is optimal treatment, $C U T_{\%}$ is the percentage of basal area to be removed in a thinning treatment, $D m_{\text {reg }}$ is the mean diameter of the stand at the first regenerative cut, $B A_{s v}$ is the basal area below which salvage cutting is optimal decision, $D m$ is the prior-thinning and prior-fire mean diameter of the trees, $B A$ is the priorcutting basal area, Poor and Good are the dummy variables defining the site quality of the stand (Poor equals 1 if the site is poor and 0 otherwise, and Good equals 1 if the site is good and 0 otherwise; on medium sites, both Poor and Good are zero), $D R$ is the discount rate, High is a dummy variable that assumes value 1 in high thinning and 0 in low thinning, and Damage is the amount of trees killed by a fire in percent of basal area. All variables of the models were significant at the $<0.001$ level (Table 1), and no collinearity nor obvious systematic biases were observed. It is noteworthy that the probability of fire was not strongly significant in the models; the $p$ values were not significant in Eq. $1(p$ value $=0.627)$, and the effect was marginal in Eq. $2(p$ value $=0.044)$ and showed significance only in Eq. 3 ( $p$ value $=0.003$ ). In this case, however, the significance was mainly due to the highest values of probability of fire occurrence (i.e., set to 0.05 ), since the moderate levels (i.e., set to 0.02 ) were not significant either ( $p$ value $=0.509)$. For this case, the value of the standardized coefficient was the lowest $(0.098)$ and its removal did not alter the predictions nor did have effects on the other variables. The probable reason for the significance and negative sign of Damage in Eq. 4 is the effect of damage rate on stand structure and mean tree size of the post-fire stand; the higher the damage rate is, the more the mean tree diameter increases after fire, decreasing the basal area limit of salvage cutting. It has to be considered that the model expressed in Eq. 1 is based on a logarithmic transformation of the dependent variable, and therefore may require a bias correction factor to retrieve 
Table 1 Regression coefficients and levels of significance of the thinning basal area model (Eq. 1), thinning intensity model (Eq. 2), regeneration cut diameter model (Eq. 3), and salvage cutting basal area model (Eq. 4)

\begin{tabular}{|c|c|c|c|c|c|}
\hline & Variable & Effect & Coefficient & SE & Significance \\
\hline Eq. 1 & & $\mathrm{~b}_{0}$ & 4.435 & 0.079 & $<0.001$ \\
\hline \multirow[t]{5}{*}{$R^{2}=0.621$} & $\sqrt{D m}$ & $\mathrm{~b}_{1}$ & -0.132 & 0.014 & $<0.001$ \\
\hline & Good & $\mathrm{b}_{2}$ & 0.187 & 0.015 & $<0.001$ \\
\hline & Poor & $b_{3}$ & -0.215 & 0.024 & $<0.001$ \\
\hline & $D R$ & $\mathrm{~b}_{4}$ & -0.089 & 0.007 & $<0.001$ \\
\hline & High & $b_{5}$ & -0.179 & 0.019 & $<0.001$ \\
\hline Eq. 2 & & $\mathrm{~b}_{0}$ & -0.478 & 0.068 & $<0.001$ \\
\hline \multirow[t]{5}{*}{$R^{2}=0.448$} & $B A$ & $b_{1}$ & 0.016 & 0.002 & $<0.001$ \\
\hline & Good & $b_{2}$ & -0.078 & 0.018 & $<0.001$ \\
\hline & Poor & $b_{3}$ & 0.194 & 0.026 & $<0.001$ \\
\hline & $D R$ & $\mathrm{~b}_{4}$ & 0.044 & 0.007 & $<0.001$ \\
\hline & High & $b_{5}$ & 0.311 & 0.023 & $<0.001$ \\
\hline Eq. 3 & & $b_{0}$ & 42.620 & 1.513 & $<0.001$ \\
\hline \multirow[t]{5}{*}{$R^{2}=0.787$} & $B A$ & $\mathrm{~b}_{1}$ & -0.197 & 0.036 & $<0.001$ \\
\hline & Good & $\mathrm{b}_{2}$ & 5.044 & 0.574 & $<0.001$ \\
\hline & Poor & $b_{3}$ & -6.145 & 0.572 & $<0.001$ \\
\hline & $D R$ & $\mathrm{~b}_{4}$ & -4.537 & 0.180 & $<0.001$ \\
\hline & High & $b_{5}$ & 1.821 & 0.117 & $<0.001$ \\
\hline Eq. 4 & & $b_{0}$ & 12.077 & 0.259 & $<0.001$ \\
\hline \multirow[t]{5}{*}{$R^{2}=0.467$} & $D m$ & $\mathrm{~b}_{1}$ & -0.099 & 0.008 & $<0.001$ \\
\hline & Poor & $\mathrm{b}_{2}$ & -3.388 & 0.079 & $<0.001$ \\
\hline & $D R$ & $\mathrm{~b}_{3}$ & -0.548 & 0.031 & $<0.001$ \\
\hline & High & $\mathrm{b}_{4}$ & -1.089 & 0.076 & $<0.001$ \\
\hline & Damage & $b_{5}$ & -0.036 & 0.002 & $<0.001$ \\
\hline
\end{tabular}

predictions in the arithmetic scale (back-transformation). The bias correction factor was calculated according to Snowdon (1991) and was 1.0063.

The resulting model for the basal area limit (Eq. 1) showed that thinning should be implemented at lower basal area when the mean diameter of the stand increases. The limit also depends on other factors, e.g., higher limits for low thinnings, especially on good quality sites, and when the discounting rates are low (e.g., 1\%). On good site and with $1 \%$ discount rate, the basal area limit is $60 \mathrm{~m}^{2} \mathrm{ha}^{-1}$ when the mean diameter is $12 \mathrm{~cm}$, and $40 \mathrm{~m}^{2} \mathrm{ha}^{-1}$ when the mean diameter is $40 \mathrm{~cm}$. The basal area limit is lower for high thinnings, poor sites, and high discounting rates. With 3\% discount rate, the basal area limit is $28 \mathrm{~m}^{2} \mathrm{ha}^{-1}$ when the mean diameter is $12 \mathrm{~cm}$, and $19 \mathrm{~m}^{2} \mathrm{ha}^{-1}$, when the mean diameter is $40 \mathrm{~cm}$.

The percentage of basal area to be removed (Eq. 2) varies depending on the pre-thinning basal area, the thinning being more intensive when the pre-thinning basal area is high, usually corresponding to early thinning. The thinning intensity also depends on the thinning method, site quality, and discount rate. For example, when a low thinning is used on medium quality sites with $2 \%$ discounting rate, the basal area to be removed is $31 \%$ when the basal area is $44 \mathrm{~m}^{2} \mathrm{ha}^{-1}$ and $9 \%$ when the basal area is $30 \mathrm{~m}^{2} \mathrm{ha}^{-1}$.

The mean diameter at first regenerative cut increases as stand basal area decreases (Eq. 3). The required diameter also increases as the site quality improves and the discounting rate decreases. The thinning method also showed an impact on regeneration diameter; low thinning resulted in smaller regeneration diameter.

The basal area of surviving trees below which salvage is recommended (Eq. 4) decreases as the mean diameter of the trees increases. This basal area limit also decreases as the damage and discounting rates increase, and when the stands are managed with high thinnings, especially on poor sites.

The models discussed above (Eqs. 1, 2, and 3) can be translated into diagrams. For example, Fig. 3 graphically depicts the basal area that activates a thinning treatment, the remaining basal area after thinning, and the diameter for initializing the regeneration cuts. The diagram shows when the stand should be left to continue growing and when a cutting should be done.

Depending on site quality, discounting rate, and thinning method, the optimal management may include none to several thinnings and start regeneration cuttings at mean tree diameter ranging from 20 to over $30 \mathrm{~cm}$ (Fig. 4). In between, the optimal management includes one thinning, and regeneration cuttings start once the stand's mean diameter is in the range of 25 to $30 \mathrm{~cm}$. In case of fire, the rule for salvage cutting shows whether it is optimal to cut the trees or continue growing with the survivors (Fig. 5).

\subsection{Soil expectation value}

A model was fitted also for predicting the economic performance of the management regime using the $S E V$ as the dependent variable (Eq. 5).

$$
\begin{aligned}
\ln \left(S E V_{+465}\right)= & b_{0}+b_{1} \text { Good }+b_{2} \text { Poor }+b_{3} \text { High } \\
& +b_{4} \text { Fpr }+b_{5} \text { Planting }+b_{6} 1 / D R \\
& +b_{7} \ln D R
\end{aligned}
$$

where $\ln S E V_{+465}$ is the natural logarithm of soil expectation value plus 465 . The amount of 465 Euros was added to the $S E V$ before making the logarithmic transformation, to avoid undefined transformation values, as the minimum $S E V$ in our database was -464.5 Euros. Fpr is the 5-year probability of fire occurrence, and Planting is a dummy variable for planting cost. Planting takes 0 when the post-fire regeneration has no cost associated, and 1 when assuming a cost of 1500 EUR $\mathrm{ha}^{-1}$. Planting cost is included in those cases where natural regeneration is not a viable option after salvage cutting. All 
Fig. 3 Rules for optimal stand management on medium quality site for high (a) and low (b) thinning. $D R$ discount rate, $D m$ mean diameter, $B A$ basal area
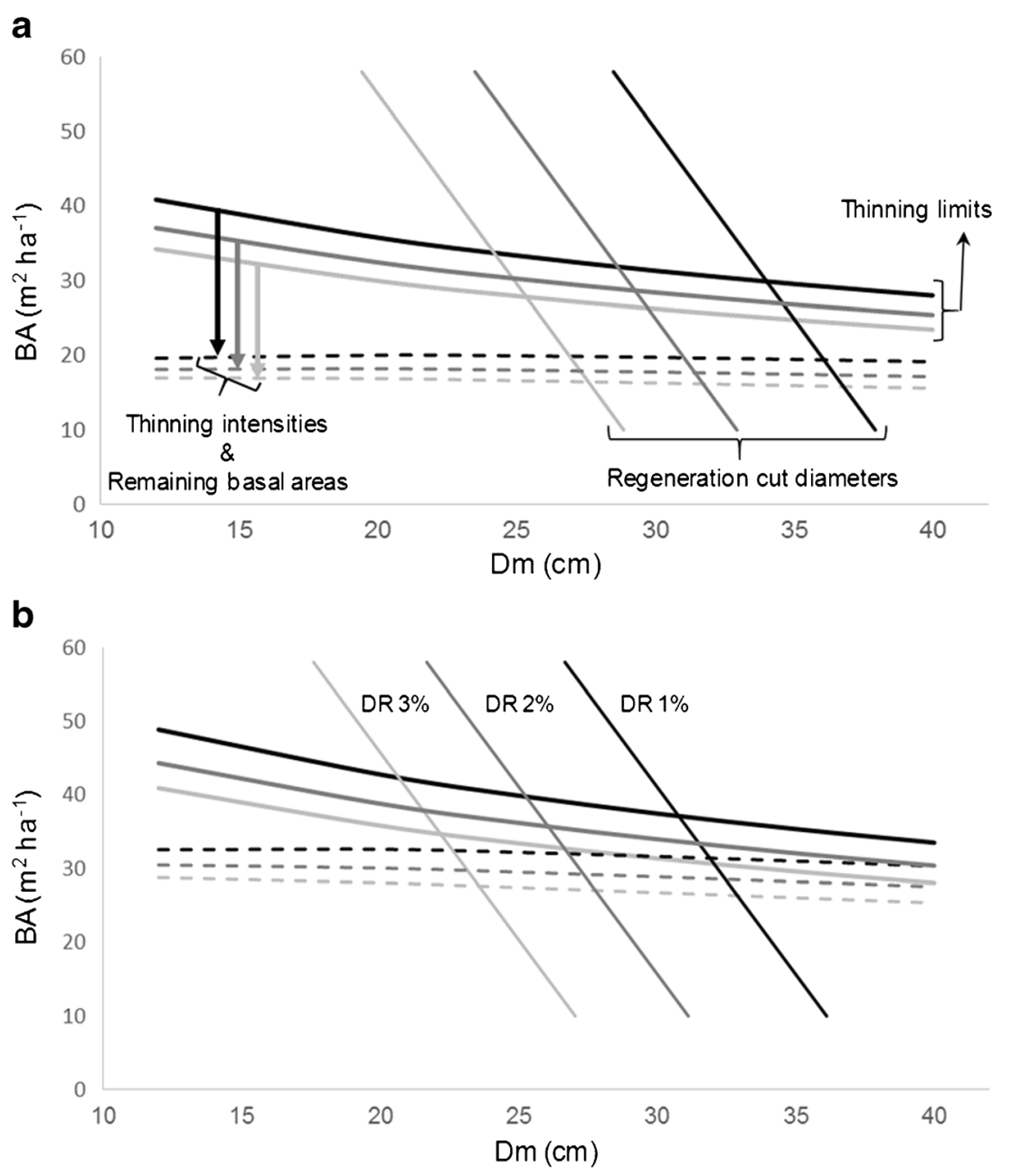

variables of the model were significant at the $<0.001$ level (Table 2), and neither collinearity nor obvious systematic biases were observed. Similar to Eq. 1, the bias correction factor was estimated, being 0.939, and it was applied to the predictions to produce estimates in the arithmetic scale.

As expected, soil expectation value increased as site quality improved, the risk of fire decreased, and no postfire planting cost was required after salvage. In addition, high thinning resulted in higher SEV than low thinning. For example, without fire risk, stand management on good sites relying on high thinning is predicted to yield $6236 \mathrm{EUR} \mathrm{ha}^{-1}$ with $1 \%$ discount rate and $818 \mathrm{EUR} \mathrm{ha}^{-1}$ with $3 \%$ discount rate. When the 5 -year fire probability is 0.05 and the planting cost is $1500 \mathrm{EUR} \mathrm{ha}^{-1}$, the predicted soil expectation value is $2264 \mathrm{EUR} \mathrm{ha}^{-1}$ with $1 \%$ discount rate and $57 \mathrm{EUR} \mathrm{ha}^{-1}$ with $3 \%$ discount rate.

\section{Discussion}

The current study incorporates various novel aspects to the process of simulating the development and management of forest stands under risk of fire, namely, the possibility of partial destruction of the stand and possibility of allowing the stand to continue growing after fire instead of implementing an obligatory salvage cutting. Contrary to studies that assume a complete damage or an automatic salvage cutting after every fire event, the results of our study are less affected by simplifying assumptions made in simulation and optimization (Pukkala 2015). Therefore, our study provides both realistic and flexible rules for the adaptive management of forest stands under the risk of fires.

The resulting rules are in many respects consistent with previous studies, suggesting shorter rotations (in our case through smaller diameters) with increasing discount rates (Reed 1984; Palahi and Pukkala 2003) and improving site quality (Zubizarreta-Gerendiain et al. 2015), or the use of high thinning to maximize profitability (Pukkala et al. 2014). Fire occurrence did not have a significant influence on the thinning regime, and only a marginal one on the rotation length (if included, the effect was merely an increase of $0.0049 \mathrm{~cm}$ on the diameter to start regeneration cuts when the fire probability moves from 0 to 0.05 ), differing from previous studies generally assuming that the optimal rotation length under risk of fire 
High Thinning
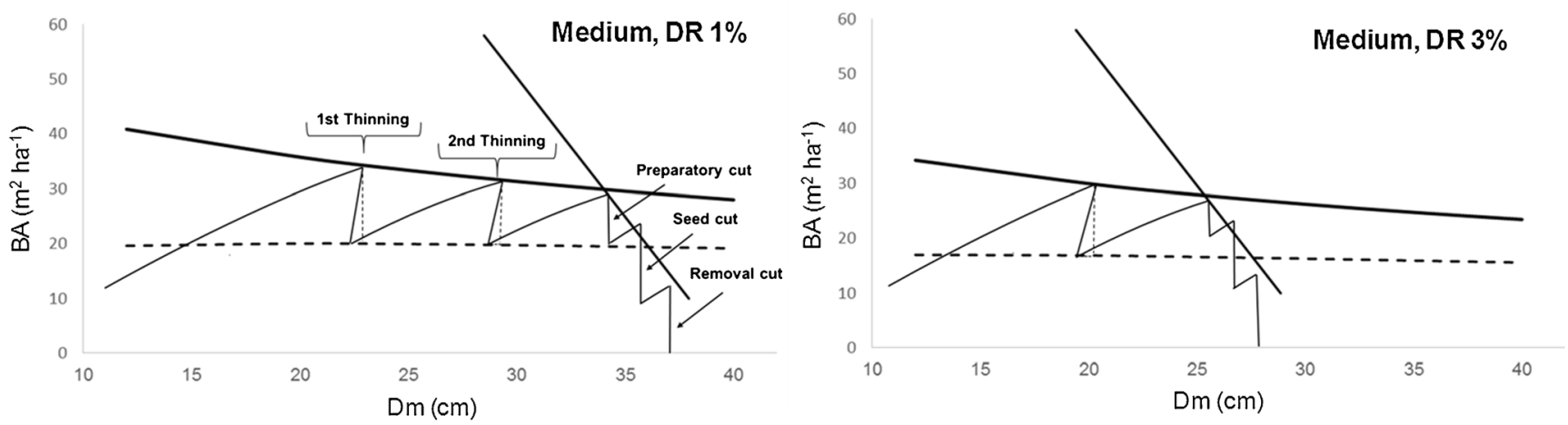

\section{Low Thinning}


Fig. 4 Examples of optimal management schedules based on the management rules and realized stand development. top High thinning, medium quality site, and discounting rates $\mathrm{DR}=1 \%$ and $\mathrm{DR}=3 \%$. down Low thinning, $\mathrm{DR}=2 \%$, and two quality sites (Good and Poor)

should be shortened as the risk increases (Martell 1980; Routledge 1980; Reed 1984; Reed and Errico 1985; Caulfield 1988; González et al. 2005). This can be explained by the endogenous nature of the damage model that we used to predict the mortality caused by fire and an increased flexibility in post-fire management. Large mature trees are the most resistant against fire and the cutting of a mature post-fire residual stand results in a very vulnerable young stand where the probability of complete damage is high. This tends to increase rotation length as fire probability increases (Pasalodos-Tato et al. 2009), or just keep it unchanged if the occurring fires have a mild impact on mortality (González-Olabarria et al. 2008). On the other hand, increasing tree size increases the opportunity cost of the growing stock and the maximum
Fig. 5 Illustration of the salvage cutting rule as a part of optimal stand management

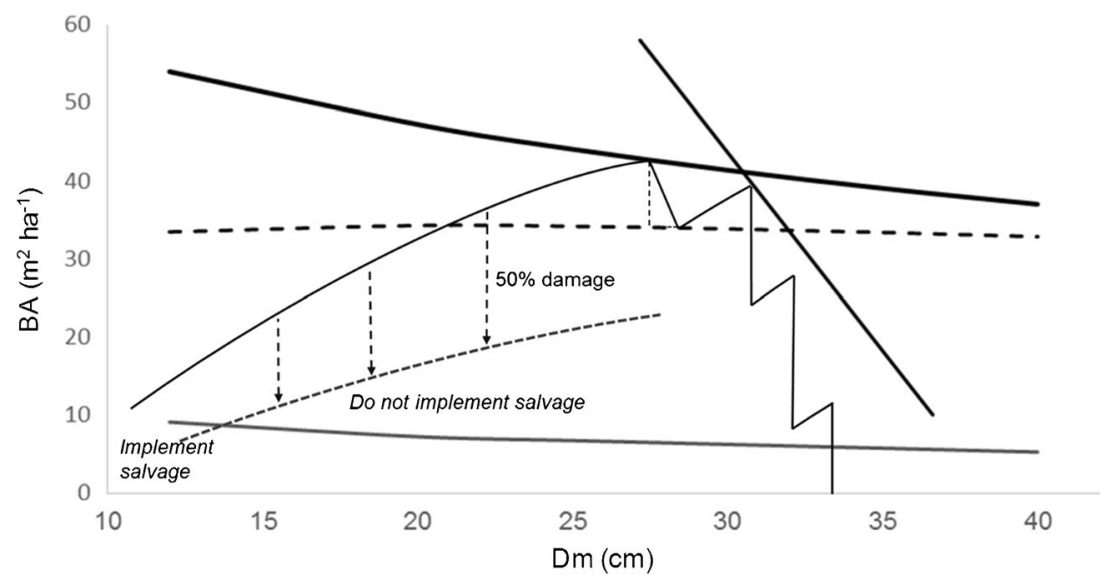


Table 2 Regression coefficients and levels of significance of the model fitted to predict the economic performance of the optimal stand management (Eq. 5)

\begin{tabular}{lllcll}
\hline & Variable & Effect & Coefficients & SE & Significance \\
\hline Eq. 5 & & $\mathrm{b}_{0}$ & 8.791 & 0.111 & $<0.001$ \\
$R^{2}=0.904$ & Good & $\mathrm{b}_{1}$ & 0.486 & 0.082 & $<0.001$ \\
& Poor & $\mathrm{b}_{2}$ & -0.823 & 0.082 & $<0.001$ \\
& High & $\mathrm{b}_{3}$ & 0.188 & 0.067 & 0.005 \\
& Fpr & $\mathrm{b}_{4}$ & -8.668 & 1.806 & $<0.001$ \\
& Planting & $\mathrm{b}_{5}$ & -0.465 & 0.071 & $<0.001$ \\
& 1/DR & $\mathrm{b}_{6}$ & -0.106 & 0.028 & $<0.001$ \\
& $\operatorname{lnDR}$ & $\mathrm{b}_{7}$ & -1.569 & 0.076 & $<0.001$ \\
\hline
\end{tabular}

possible economic loss in case of fire. Our study suggests that these effects largely cancel each other making the optimal rotation length insensitive to the probability of fire.

As expected, fire risk has a strong negative impact on the economic profitability of forestry due to increased mortality, reduced timber price, and additional costs of post-fire planting (González-Olabarria et al. 2008). The effects of variables included in the model for soil expectation value were logical; soil expectation value increases as site quality improves (Zubizarreta-Gerendiain et al. 2016), and high thinnings result in better profitability than low thinning (Haight and Monserud 1990; Hyytiäinen et al. 2005; Pukkala et al. 2014). The severity of fire damage influences the limiting basal area for implementing salvage cutting. In general, salvage cuttings are to be implemented if natural regeneration is not ensured or the post-fire living stock is reduced so much that the relative value increment of the survivors falls below the opportunity cost of growing stock and land.

As mentioned, the application of our cutting rules depends on the development of the stand. This means that our approach allows adapting the management on the basis of the realized growth and fire events. The decision of implementing salvage should be taken soon after the fire, in order to reduce further timber depreciation (Sessions et al. 2004). However, post-fire tree mortality does not stabilize until the third year after the fire (Ryan and Reinhardt 1988). Therefore, predictions about the expected mortality of trees are required until mortality can be measured reliably. These predictions can be based on models, e.g., the mortality model of González et al. (2007), which has been developed for the purpose of integrating fire risk into strategic or tactical forest planning. However, when a fire occurs, information on fire severity can be gathered few weeks after the fire, after which traditional post-fire mortality models as the one of Fernandes et al. (2012) can be used for obtaining more accurate predictions of post-fire mortality and subsequently on surviving basal area and mean diameter.

By maximizing only the SEV, without considering fire prevention objectives, the obtained management alternatives reflect the relatively low economic efficiency of managed forest stands in Catalonia. In this region, highly productive forests are not common and low timber prices limit the implementation of costly management operations, such as planting or thinnings from below. In a way, the results support the so-called "negligence management" often chosen by forest owners in the region, who usually implement cuttings only when the timber stock and tree sizes allow removing enough timber to cover the managerial costs and get some income from the timber sale (Aunos et al. 2009), or when the operations are subsidized as a fire prevention measure. Although in the analysis we only selected basic management operations for improving the state of the forest, with a clearly economic objective, such as thinnings, regenerative cuttings, and post-fire salvage cuttings, other management options can be considered if a broader reality is imagined. Considering the impact of fire on other services that forests provide, for instance, non-wood forest products and soil and watershed protection (Merlo and Croitoru 2005; Selkimäki et al. 2012), and the costs associated with fire extinction activities, other management operations that aim at reducing fire risk, such as shrub cleaning, would most probably be justified. Additionally, social awareness concerning wildfires and the willingness to pay for fire prevention measures (Farreras and Mavsar 2012) are aspects that should be considered in forest management. Economically optimal management, focused only on timber production, seldom reflects the overall reality of Mediterranean forests (Palahi et al. 2008).

In conclusion, we presented an approach that provides valuable information for the optimal management of Catalonian P. nigra stands under the risk of fire. Our approach supports adaptive decisions such as performing salvage cuttings after severe fires. We provided a set of adaptive management rules, which advise forest managers in case of sudden fires that may change the state of the forest and may invalidate previously developed management prescriptions.

\section{Compliance with ethical standards}

Funding CTFC authors acknowledge funding from MINECO (Ref. RYC-2011-08983, RYC-2013-14262, AGL2015-67293-R MINECO/ FEDER) and from CERCA Programme/Generalitat de Catalunya. José Ramón González also thanks the José Castillejo program of the Ministry of Education, Culture, and Sport for facilitating the mobility grant required for the implementation of the study. 


\section{Appendix}

Table 3 Representation of 8 of the 270 optimal managements and variables recorded on the database used for modeling (salvage model required from an additional database)

\begin{tabular}{|c|c|c|c|c|c|c|c|c|c|c|c|c|c|c|c|c|}
\hline Thinning & Pcost & Year & Cut type & GI & Disk rate & FireProb & $\mathrm{N}$ & G & V & $\mathrm{D}$ & $\mathrm{H}$ & RemVol & Gross & Cost & Net & Mean SEV \\
\hline 0 & 0 & 95 & 1 & 1 & 0.1 & 0 & 746.8 & 33.7 & 197.9 & 27.5 & 12.7 & 40.8 & $1,262.7$ & 785.1 & 477.6 & $30,768.3$ \\
\hline 0 & 0 & 110 & 2 & 1 & 0.1 & 0 & 395.6 & 28.1 & 174.9 & 32.3 & 13.8 & 46.9 & $1,528.4$ & 762.7 & 765.7 & $30,768.3$ \\
\hline 0 & 0 & 120 & 3 & 1 & 0.1 & 0 & 217.1 & 21.2 & 139.2 & 36.6 & 14.7 & 71.2 & $2,412.0$ & 981.7 & $1,430.2$ & $30,768.3$ \\
\hline 0 & 0 & 130 & 4 & 1 & 0.1 & 0 & 77.6 & 10.8 & 74.9 & 42.4 & 15.6 & 74.9 & $2,621.8$ & 849.5 & $1,772.3$ & $30,768.3$ \\
\hline 0 & 0 & 80 & 1 & 1 & 0.6 & 0 & 923.1 & 32.4 & 181.5 & 24.0 & 11.9 & 25.6 & 752.9 & 562.1 & 190.8 & $3,802.8$ \\
\hline 0 & 0 & 95 & 2 & 1 & 0.6 & 0 & 544.0 & 29.8 & 176.9 & 28.5 & 13.0 & 54.6 & $1,740.1$ & 962.5 & 777.6 & $3,802.8$ \\
\hline 0 & 0 & 105 & 3 & 1 & 0.6 & 0 & 276.6 & 21.6 & 135.6 & 32.9 & 14.0 & 70.0 & $2,324.8$ & $1,056.6$ & $1,268.2$ & $3,802.8$ \\
\hline 0 & 0 & 115 & 4 & 1 & 0.6 & 0 & 93.0 & 11.0 & 73.7 & 39.0 & 15.1 & 73.7 & $2,555.2$ & 897.5 & $1,657.7$ & $3,802.8$ \\
\hline 0 & 0 & 75 & 2 & 1 & 1.1 & 0 & 990.3 & 31.7 & 174.7 & 22.9 & 11.6 & 61.3 & $1,844.1$ & $1,276.0$ & 568.1 & $1,561.0$ \\
\hline 0 & 0 & 85 & 3 & 1 & 1.1 & 0 & 412.9 & 22.2 & 130.4 & 27.5 & 12.8 & 69.2 & $2,226.3$ & $1,183.9$ & $1,042.5$ & $1,561.0$ \\
\hline 0 & 0 & 95 & 4 & 1 & 1.1 & 0 & 134.3 & 11.3 & 71.6 & 33.3 & 14.1 & 71.6 & $2,425.6$ & 990.6 & $1,435.1$ & $1,561.0$ \\
\hline 0 & 0 & 70 & 2 & 1 & 1.6 & 0 & $1,061.4$ & 30.9 & 167.2 & 21.7 & 11.2 & 56.2 & $1,666.7$ & $1,210.8$ & 456.0 & 800.4 \\
\hline 0 & 0 & 80 & 3 & 1 & 1.6 & 0 & 462.8 & 22.4 & 129.2 & 26.1 & 12.5 & 69.1 & $2,202.4$ & $1,225.3$ & 977.1 & 800.4 \\
\hline 0 & 0 & 90 & 4 & 1 & 1.6 & 0 & 148.9 & 11.4 & 71.1 & 31.8 & 13.8 & 71.1 & $2,391.2$ & $1,018.6$ & $1,372.6$ & 800.4 \\
\hline 0 & 0 & 60 & 2 & 1 & 2.1 & 0 & $1,213.7$ & 28.6 & 149.6 & 19.3 & 10.5 & 43.5 & $1,243.4$ & $1,017.8$ & 225.7 & 449.3 \\
\hline 0 & 0 & 70 & 3 & 1 & 2.1 & 0 & 591.2 & 23.0 & 126.9 & 23.3 & 11.8 & 69.4 & $2,160.6$ & $1,324.5$ & 836.1 & 449.3 \\
\hline 0 & 0 & 80 & 4 & 1 & 2.1 & 0 & 186.0 & 11.7 & 70.2 & 28.8 & 13.2 & 70.2 & $2,322.4$ & $1,082.3$ & $1,240.1$ & 449.3 \\
\hline 0 & 0 & 60 & 2 & 1 & 2.6 & 0 & $1,213.7$ & 28.6 & 149.6 & 19.3 & 10.5 & 43.5 & $1,243.4$ & $1,017.8$ & 225.7 & 260.9 \\
\hline 0 & 0 & 70 & 3 & 1 & 2.6 & 0 & 591.2 & 23.0 & 126.9 & 23.3 & 11.8 & 69.4 & $2,160.6$ & $1,324.5$ & 836.1 & 260.9 \\
\hline 0 & 0 & 80 & 4 & 1 & 2.6 & 0 & 186.0 & 11.7 & 70.2 & 28.8 & 13.2 & 70.2 & $2,322.4$ & $1,082.3$ & $1,240.1$ & 260.9 \\
\hline 0 & 0 & 55 & 2 & 1 & 3.1 & 0 & $1,293.5$ & 27.2 & 139.4 & 18.0 & 10.2 & 35.8 & 996.4 & 882.5 & 113.9 & 151.9 \\
\hline 0 & 0 & 65 & 3 & 1 & 3.1 & 0 & 675.4 & 23.3 & 126.0 & 21.9 & 11.4 & 69.8 & $2,144.0$ & $1,384.9$ & 759.1 & 151.9 \\
\hline 0 & 0 & 75 & 4 & 1 & 3.1 & 0 & 209.9 & 11.9 & 69.8 & 27.3 & 12.8 & 69.8 & $2,288.1$ & $1,119.1$ & $1,169.0$ & 151.9 \\
\hline 0 & 0 & 50 & 2 & 1 & 3.6 & 0 & $1,374.3$ & 25.5 & 128.4 & 16.8 & 9.8 & 27.1 & 739.1 & 693.5 & 45.6 & 86.2 \\
\hline 0 & 0 & 60 & 3 & 1 & 3.6 & 0 & 822.8 & 23.7 & 124.9 & 20.3 & 10.9 & 70.2 & $2,109.3$ & $1,469.7$ & 639.7 & 86.2 \\
\hline 0 & 0 & 70 & 4 & 1 & 3.6 & 0 & 239.0 & 12.1 & 69.5 & 25.8 & 12.5 & 69.5 & $2,254.1$ & $1,160.2$ & $1,093.9$ & 86.2 \\
\hline
\end{tabular}

The recorded variables being from left to right, the thinning method (in this case 0 means that low thinning was considered), the planting cost applied $\left(E U R h^{-1}\right)$, the year an operation was implemented, the type of operation ( 1 for thinning, 2 for preparatory cutting, 3 for disseminatory cutting, and 4 for final cutting), the growth index (unitless, is a ratio between measured and predicted tree growth that modifies the site quality), the discounting rate (\%), the fire probability (5-year probability), the number of trees (trees ha $\left.{ }^{-1}\right)$, the basal area $\left(\mathrm{m}^{2} \mathrm{ha}^{-1}\right)$, the timber volume $\left(\mathrm{m}^{3} \mathrm{ha}^{-1}\right)$, the mean diameter $(\mathrm{cm})$, the mean tree height $(\mathrm{m})$, the removed volume per cutting $\left(\mathrm{m}^{3} \mathrm{ha}^{-1}\right)$, the gross income (EUR ha ${ }^{-1}$ ), the cost of the operation (EUR ha $\left.{ }^{-1}\right)$, the net income $\left(\right.$ EUR $\left.\mathrm{ha}^{-1}\right)$, and the soil expectation value $\left(\mathrm{EUR} \mathrm{ha}{ }^{-1}\right)$

\section{References}

Arenas-Ruiz SG, Izquierdo-Osorio S (2007) Estudio de los precios de la madera en pie de los montes gestionados por la administración forestal gallega en los años 2005 y 2006. Revista Montes 90:8-15

Aunos A, Riba A, Blanco R (2009) Caracterización selvícola de las masas monoespecíficas de pino laricio en Cataluña. Inv Agrar-Sist Recursos Fores 18:338-349

Bazaraa MS, Shetty CM (1979) Nonlinear programming, theory and algorithms. John Wiley \& Sons, New York

Caulfield JP (1988) A stochastic efficiency approach for determining the economic rotation of a forest stand. For Sci 34:441-457

Englin J, Baxall P, Hauer G (2000) An empirical examination of optimal rotations in a multiple-use forest in the presence of fire risk. J Agric Res Econ 25:14-27

Farreras V, Mavsar R (2012) Burned forest area or dead trees? A discrete choice experiment for Catalan citizens. Economía Agraria y Recursos Naturales 12:137-153. doi:10.7201/earn.2012.02.06

Faustmann M (1849) Calculation of the value which forest land and immature stands possess for forestry. Allg Forst Jagdztg $15: 441-455$
Fernandes PM, Fernandes MM, Loureiro C (2012) Survival to prescribed fire of plantation-grown Corsican black pine in northern Portugal. Ann For Sci 69:813-820. doi:10.1007/s13595-012-0211-6

Ferreira L, Constantino M, Borges JG (2014) A stochastic approach to optimize maritime pine (Pinus pinaster Ait.) stand management scheduling under fire risk. An application in Portugal. Ann Oper Res 219:359-377. doi:10.1007/s10479-011-0845-z

Garcia-Gonzalo J, Pukkala T, Borges JG (2014) Integrating fire risk in stand management scheduling. An application to maritime pine stands in Portugal. Ann Oper Res 219:379-395. doi:10.1007/s10479-011-0908-1

González JR, Pukkala T (2007) Characterization of forest fires in Catalonia (north-east Spain). Eur J For Res 126:421-429. doi:10. 1007/s10342-006-0164-0

González JR, Pukkala T, Palahí M (2005) Optimising the management of Pinus sylvestris L. stand under risk of fire in Catalonia (northeast of Spain). Ann For Sci 62:493-501. doi:10.1051/forest:2005054

Gonzalez JR, Palahi M, Trasobares A, Pukkala T (2006) A fire probability model for forest stands in Catalonia (north-east Spain). Ann For Sci 63:169-176. doi:10.1051/forest:2005109

González JR, Trasobares A, Palahí M, Pukkala T (2007) Predicting stand damage and tree survival in burned forests in Catalonia (north-east Spain). Ann For Sci 64:733-742. doi:10.1051/forest:2007053 
González-Olabarria JR, Palahí M, Pukkala T, Trasobares A (2008) Optimising the management of Pinus nigra Arn. stands under endogenous risk of fire in Catalonia. Inv Agrar-Sist Recursos Fores 17: $10-17$

Haight RG, Monserud RA (1990) Optimizing any-aged management of mixed-species stands, II. Effects of decision criteria. For Sci 36:125144

Hooke R, Jeeves TA (1961) "Direct search" solution of numerical and statistical problems. J Assoc Comput Mach 8:212-229. doi:10. $1145 / 321062.321069$

Hyytiäinen K, Haight RG (2010) Evaluation of forest management systems under risk of wildfire. Eur J For Res 129:909-919. doi:10. 1007/s10342-009-0278-2

Hyytiäinen K, Tahvonen O, Valsta L (2005) Optimum juvenile density, harvesting and stand structure in even-aged Scots pine stands. For Sci 51:120-133

Kuboyama H, Oka H (2000) Climate risks and age-related damage probabilities - effects on the economically optimal rotation length for forest stand management in Japan. Silva Fenn 34:155-166. doi:10. 14214/sf.637

Lohmander P (2007) Adaptive optimization of forest management in a stochastic world. In: Weintraub A et al (eds) Handbook of operations research in natural resources. Springer, New York, pp 525-543

Martell DL (1980) The optimal rotation of a flammable forest stand. Can J For Res 10:30-34. doi:10.1139/x80-006

Merlo M, Croitoru L (2005) Valuing Mediterranean forests-towards total economic value. CABI Publishing

Ordóñez JL, Retana J, Espelta JM (2005) Effects of tree size, crown damage, and tree location on post-fire survival and cone production of Pinus nigra trees. For Ecol Manag 206:109-117. doi:10.1016/j. foreco.2004.10.067

Ordoñez JL, Molowny-Horas R, Retana J (2006) A model of the recruitment of Pinus nigra from unburned edges after large wildfires. Ecol Model 197:405-417. doi:10.1016/j.ecolmodel.2006.03.027

Palahí M, Grau-Corbí J (2003) Site index model and individual-tree growth and mortality models for black pine (Pinus nigra Arn.) in Catalonia (Spain). Inv Agrar-Sist Recursos Fores 12:137-148

Palahi M, Pukkala T (2003) Optimising the management of Scots pine (Pinus sylvestris L.) stands in Spain based on individual-tree models. Ann For Sci 60:105-114. doi:10.1051/forest:2003002

Palahi M, Mavsar R, Gracia C, Birot Y (2008) Mediterranean forest under focus. Int For Rev 10:676-688. doi:10.1505/ifor.10.4.676

Pasalodos-Tato M, Pukkala T, Castedo-Dorado F (2009) Models for the optimal management of Pinus radiata D. Don in Galicia (northwestern Spain) under risk of fire. Allg Forst Jagdztg 180:238-249

Pasalodos-Tato M, Pukkala T, Alboreca AR (2010) Optimal management of Pinus pinaster in Galicia (Spain) under risk of fire. Int J Wildland Fire 19:937-948. doi:10.1071/wf08150
Puerta-Piñero C, Brotons L, Coll L, González-Olabarría JR (2012) Valuing acorn dispersal and resprouting capacity ecological functions to ensure Mediterranean forest resilience after fire. Eur J For Res 131:835-844. doi:10.1007/s10342-011-0557-6

Pukkala T (2015) Optimizing continuous cover management of boreal forest when timber prices and tree growth are stochastic. For Ecosyst 2:1-13. doi:10.1186/s40663-015-0028-5

Pukkala T, Kellomäki S (2012) Anticipatory vs adaptive optimization of stand management when tree growth and timber prices are stochastic. Forestry 85:463-472. doi:10.1093/forestry/cps043

Pukkala T, Miina J, Kurttila M, Kolström T (1998) A spatial yield model for optimizing the thinning regime of mixed stands of Pinus sylvestris and Picea abies. Scand J For Res 13:31-42

Pukkala T, Lände E, Laiho O (2014) Stand management optimizationthe role of simplifications. For Ecosyst 1:1-11. doi:10.1186/21975620-1-3

Reed WJ (1984) The effects of the risk of fire on the optimal rotation of a forest. J Environ Manag 11:180-190. doi:10.1016/0095-0696(84) 90016-0

Reed WJ, Errico D (1985) Assessing the long-run yield of a forest stand subject to the risk of fire. Can J For Res 20:961-969. doi:10.1139/ $\mathrm{x} 85-111$

Routledge RD (1980) The effect of potential catastrophic mortality and other unpredictable events on optimal forest rotation policy. For Sci 26:389-399

Ryan KC, Reinhardt ED (1988) Predicting postfire mortality of seven western conifers. Can J For Res 18:1291-1297. doi:10.1139/x88199

Selkimäki M, González-Olabarria JR, Pukkala T (2012) Site and stand characteristics related to surface erosion occurrence in forests of Catalonia (Spain). Eur J For Res 131:739-746. doi:10.1007/ s10342-011-0545-X

Sessions J, Bettinger P, Buckman R, Newton M, Hamann J (2004) Hastening the return of complex forests following fire, the consequences of delay. J For 10:38-45

Snowdon P (1991) A ratio estimator for bias correction in logarithmic regressions. Can J For Res 21:720-724

Solano JM, Fernández J, Palahí M, Pukkala T, Prokofieva I (2007) ¿Es rentable la gestión forestal en Cataluña? Economistas 113:116-124

Zubizarreta-Gerendiain A, Pukkala T, Kellomäki S, Garcia-Gonzalo J, Ikonen VP, Peltola H (2015) Effects of climate change on optimised stand management in the boreal forests of central Finland. Eur J For Res 134:273-280. doi:10.1007/s10342-014-0849-8

Zubizarreta-Gerendiain A, Pukkala T, Peltola H (2016) Effects of wood harvesting and utilisation policies on the carbon balance of forestry under changing climate, a Finnish case study. Forest Policy Econ 62: 168-176. doi:10.1016/j.forpol.2015.08.007 